asthmatic patient's restlessness and irrational behaviour is due to his anoxaemia and hypercarbia and can be safely relieved only by adequate ventilation. So far as the actual management of status asthmaticus is concerned, I am again highly surprised to see so many experts putting such great accent on the use of corticosteroids without mention of the fundamental approach of hydration of the patient in status asthmaticus. This is imperative if we are to encourage the thinning out and eventual expectoration of the driedup secretions and mucous plugs. Undetected respiratory infections have been reported as one of the causes of death in bronchial asthma, and a high index of suspicion with prompt and adequate institution of an appropriate antibiotic therapy could save many lives.

Finally, close follow-up of the clinical picture as well as frequent evaluation of the level of blood gases and the availability of a team of trained personnel for possible assisted respiration is invaluable if we are to do all in our power to save these patients.-I am, etc..

$$
\begin{aligned}
& \text { Department of Allergy } \\
& \text { and Immunology, } \\
& \begin{array}{l}
\text { Grand View Hospital. } \\
\text { Sellersville, Penns:'vania, U.S.A. SABOKAR. }
\end{array}
\end{aligned}
$$

SIR,-I was very much intrigued by the articles by Dr. F. E. Speizer and others (10 February, pp. 335 and 339) on the subject of mortality from asthma and your leading article (p. 329) on the same subject. However, it was singularly unfortunate that Speizer and his co-workers chose the year 1952 as the baseline for their studies. I believe that had they gone back a little more than a score years before the issue would have come into better focus, in particular the effect of the steroids.

Writing on the same subject in an article entitled "A Historical Account of Death from Asthma," Professor H. L. A. Alexander states that we may recognize three periods during which the occurrence of death from asthma showed a characteristic trend. The first is measured by a century, the second by a few decades, and the third by a few years.

Quoting directly from Dr. Alexander's paper: "The first ended about the year 1930. Prior to this date death during an asthmatic attack was almost unknown. To be sure, in that era there was less clinical material in terms of hospital population, fewer autopsies, fewer medical periodicals, and fewer opportunities to present cases at medical meetings, compared to facilities of the present day. Nevertheless, the evidence that death during an asthmatic paroxysm was exceedingly uncommon is overwhelming.

"During the succeeding 25 years there was, at first, a gradual increase in the number of reported deaths from asthma (187 instances had been assembled in 1937), and after that there was an acceleration in the number of fatalities. According to the National Vital Statistics Division of the United States Public Health Service, under the designation 'Deaths from Asthma,' the peak occurred between the years 1951 and 1953. During the latter year there were 6,737 such deaths. More dramatic still was the New Zealand experience, where the death rate from asthma rose from 1.7 in 1939 to 10.4 [per 100,000] in 1953.

"Approximately after the year 1953 there appeared to be a decided diminution in the number of asthmatic deaths. The apparent abrupt decline in fatalities appeared at a time when cortisone and related hormones were coming to be used extensively in the treatment of asthma."-I am, etc.,

$$
\text { Hayward, }
$$

$$
\text { California, U.S.A. }
$$

\section{J. J. RobBins.}

REFERENCES

1 Alexander, H. L. A., f. Allergy, 1963, 34, 305.

SIR,-In answer to Dr. B. H. Gandevia (6 April, p. 50), we wished in our letter (2 March, p. 575) to emphasize the importance of a rising arterial carbon-dioxide tension $\left(\mathrm{PaCO}_{2}\right)$ in a severe attack of asthma as a sign of serious deterioration and of having a significance quite different from this finding in a bronchitic patient.

He appears to have misunderstood the point of our paper ${ }^{1}$ to which he refers, which was a comparison between spirometry and blood-gas tensions in asthmatics and bronchitics, where we found that, although they may have comparable airway obstruction and hypoxaemia, bronchitics have significantly higher $\mathrm{PaCO}_{2}$ levels, but at this stage in the asthmatic the $\mathrm{PaCO}_{2}$ is normal or even reduced owing to hyperventilation. Hypercapnia in the bronchitic is usually of some standing, and compensatory mechanisms have been brought into play, but in the asthmatic hypercapnia usually develops over a short period and often increases rapidly, so that there is no time for adjustment of homeostatic mechanisms. This leads to falls in cerebrospinal fluid $\mathrm{pH}$, and in addition, as the $\mathrm{PaCO}_{2}$ level rises acutely, they are unable to maintain adequate oxygen saturation because the arterial oxygen tension falls markedly. These changes, we think, contribute to failure of respiratory and vasomotor centres, which seems likely to be the cause of the sudden and unexpected deterioration which occurs in severe asthma and which not infrequently leads to death. For these reasons we are in full agreement with Dr. P. Meisner and Dr. P. Hugh-Jones (24 February, p. 470) and others, ${ }^{2}$ who regard a rising $\mathrm{PacO}$ level as heralding a severe emergency, which is of ten followed by death unless ventilation is artificially achieved.-We are, etc.,

$$
\text { K. N. V. Palmer. }
$$

\section{L. Diament.}

\section{Department of Medicine,
University of Aberdeen}

\section{REFERENCES}

Palmer, K. N. V., and Diament, M. L., Lancet, 1967, 2, 383.

Marchand, P., and van Hasselt, H., Lancet, 1966, 1, 22?

\section{Atrial Septostomy}

SIR,-Further to the memorandum. by Dr. S. P. Singh and his colleagues on the haemodynamic effects of balloon septostomy in tricuspid atresia (27 January, p. 225), which suggests that this procedure should decrease central venous pressure and relieve cardiac failure, we should like to report an additional case with further details.

The patient was noted to be breathless from birth when feeding, at 5 weeks cyanosis was obvious, and she developed cardiac failure following a respiratory tract infection. Examination showed central cyanosis, sinus rhythm $140 / \mathrm{min}$., the apex beat was not displaced, there were no thrills, the second sound in the pulmonary area was normal in intensity and single, there was a grade $2 / 6$ pansystolic murmur at the lower right sternal border, but no diastolic murmurs. The liver was enlarged two fingerbreadths, the chest was clear, and the respiratcry rate $40 / \mathrm{min}$. Chest radiography showed situs solitus, and cardiomegaly with reduced pulmonary vascularity. The electrocardiogram showed sinus rhythm 120 (axis $\left.-30^{\circ}\right)$, gross right atrial $(4 \mathrm{~mm}$.) and left ventricular hypertrophy.

Cardiac catheterization with right atrial and left ventricular angiocardiography confirmed the diagnosis of tricuspid atresia with a ventricular septal defect and normally related great vessels. In view of the $P$ waves of $4 \mathrm{~mm}$. and a right atrial pressure of $25 \mathrm{~mm}$., it was decided to perform an atrial septostomy. This was done initially with a No. 4 Rashkind catheter with 2.5 $\mathrm{ml}$. of dye in the balloon. This burst during the procedure and a No. 5 Fcgarty embelectomy balloon catheter was then used with 2.0 followed by $2.5 \mathrm{ml}$. of dye in the balloon. This produced a reduction in right atrial pressure from 25 to $12 \mathrm{~mm}$. Hg. Initially difficulty was experienced in visualizing the non-opaque embolectomy catheter, but this was overcome by partially filling it with radio-opaque dye. The Fogarty catheter and balloon, as pointed out by Dr. Singh and his colleagues, are more robust, cheaper, and more easily available in a greater variety of sizes than the Rashkind instrument. Although the latter has the advantage of giving a direct pressure measurement in the larger sizes, this is not found in the No. 4 , which may be more frequently used in small children.

Our patient showed an initial improvement over the first 48 hours following the procedure, but subsequently developed progressive cardiac failure and died on the seventh post-operative day. Necropsy showed the foramen ovale to have been split open completely (see Figure).

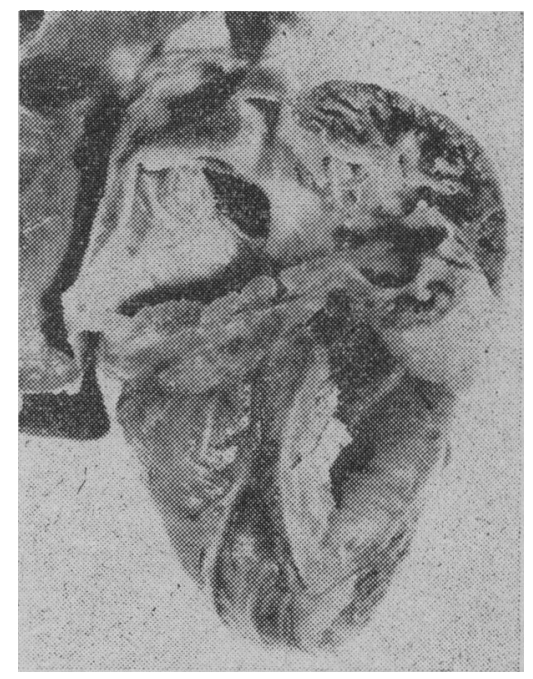

Right postero-lateral view of partly dissected heart with lateral surface of right atrium reflected. Right atrium is above, and the central dark area represents the deficiency in the atrial septum as a result of the Rashkind procedure.

We would suggest that atrial septostomy should be regarded with some circumspection following the death of both the infants reported, although their condition at the time of operation was poor; certainly this small experience contrasts badly with the largely good results we have obtained with the Rashkind procedure used in infants with transposition of the great vessels.-We are, etc.,

\section{JOHN HAMILL.}

Douglas Pickering.

Peter Sieight.

Cardiac Department, Oxford. 